\title{
Diversification of the Ig Variable Region Gene Repertoire of Synovial B Lymphocytes by Nucleotide Insertion and Deletion
}

\author{
Yasushi Miura, ${ }^{1,2}$ Charles C Chu, ${ }^{1,2}$ David M Dines, ${ }^{3}$ Stanley E Asnis, $^{4}$ Richard A Furie, ${ }^{1,2}$ \\ AND Nicholas Chiorazzi ${ }^{1,2}$
}

\begin{abstract}
Although the changes that occur in Ig $\vee$ region genes during a $B$ lymphocyte's response to antigen usually result from point mutations, nucleotide insertion and deletion also alter gene sequence. We identified nucleotide insertions and deletions (3 to $12 \mathrm{bp}$ ) at a frequency of $1.34 \%$, in Ig $\mathrm{V}$ gene cDNA from B lymphocytes residing in the synovial tissues of patients with rheumatoid arthritis. Because the added or lost nucleotides occurred in multiples of 3 , they maintained the original reading frame and coded a potentially intact receptor. These $V$ gene modifications were generated somatically, because they were identified in the original CDNA by HCDR3-specific polymerase chain reaction and were not found in other B cells using the same $V_{H}$ genes. Insertions and deletions were detected only in $\operatorname{lgG}^{+}$and $\operatorname{lgA}^{+}$transcripts, which exhibited 3 times more point mutations than $\lg ^{+}$transcripts. In addition, they were usually found in the complementarity determining region, typical targets of somatic mutation. The occurrence of insertion/ deletion in isotype-switched cDNA with higher numbers of $\vee$ gene mutations that localized to hot spots for $\vee$ gene mutation suggests that these diversification events were related to the somatic hypermutation process. In support of this, an AGY hot spot motif and a short stretch of DNA similar in sequence to the inserted or deleted segments could be found next to the insertions/deletions, suggesting that these modifications arose from DNA duplication following DNA stand breaks. Thus, nucleotide insertion/deletion can lead to B-cell receptor diversification in B lymphocytes that clonally expand in synovial tissues of patients with rheumatoid arthritis.
\end{abstract}

\section{INTRODUCTION}

The generation of antigen binding diversity occurs at 2 distinct phases of B lymphocyte development. The primary antigen binding repertoire evolves in the bone marrow with the rearrangement of $\mathrm{V},(\mathrm{D})$, and J elements followed by association of $\mathrm{Ig} \mathrm{H}$ and $\mathrm{L}$ chains $(1,2)$. This process is evolutionary because the initial set of $\mathrm{V},(\mathrm{D})$, and J elements can be modified by a process of secondary rearrangements if the initial antibody produced does not act as an acceptable or beneficial receptor. This process is termed receptor editing (3-5). B cells with acceptable antigenic specificities then proceed to the periphery as functional lymphocytes.

In peripheral lymphoid structures, these B cells mature further and evolve $V$ region modifications that expand antigen-binding diversity within (6), and probably outside of (7-9), classical germinal centers. These $\mathrm{V}$ region changes occur via several mechanisms: point mutation (6), gene replacement (3-5,10-13), and nucleotide insertion and deletion (14-16). Although these receptor modifications could lead to autoreactivity, they do not normally lead to permanently viable B cells with self-reactive receptors because of relatively stringent selection processes that favor reactivity with foreign antigens and abort B cells with significant avidity for autoantigens. In certain autoimmune disorders, inef- fective selection against autoreactivity may occur because of genetic or acquired defects in immunoregulation.

B lymphocytes and their products play an essential role in the pathogenesis of rheumatoid arthritis (RA) by perpetuating and potentiating chronic, destructive inflammatory synovitis (17). The proinflammatory activity of B cells relates to their activity in presenting antigen to $\mathrm{T}$ cells and in producing antibodies with autoantigenic specificity to human IgG (rheumatoid factor [RF]) $(18,19)$ and to other less well-defined tissue antigens $(20,21)$ and possibly environmental antigens (22-24). In addition, data derived from a novel animal model suggest that specific B lymphocyte clones and their secreted antibody may play a role in the initiation of an RA-like syndrome (25-27).

In RA, the expanding $B$ lymphocyte clones can diversify their Ig V genes (28-30) locally in the synovium $(29,31)$. While studying the clonally amplified B lymphocytes in the synovial tissues of RA patients, we identified $\mathrm{V}_{\mathrm{H}} \mathrm{DJ}_{\mathrm{H}}$ cDNA clones that exhibited nucleotide insertions and deletions. Because these nucleotide insertions and deletions occurred in multiples of 3 , they maintained the original reading frames and could code an effective Ig molecule and B-cell antigen receptor. The majority of these changes occurred in isotype-switched B cells, within the hypervariable regions at trinucleotide hot spots for somatic mutation

\footnotetext{
${ }^{1}$ Center for Immunology \& Inflammation, North Shore-LIJ Research Institute, Manhasset, NY; ${ }^{2}$ Departments of Medicine, North Shore University Hospital and New York University School of Medicine, Manhasset, NY; ${ }^{3}$ Departments of Surgery, Long Island Jewish Medical Center and Albert Einstein College of Medicine, New Hyde Park, NY; and ${ }^{4}$ Departments of Surgery, North Shore University Hospital and New York University School of Medicine, Manhasset, NY.
} 
(AGY motifs). Because "misalignment feet" motifs (32-35) and palindromic sequences were frequently found near these insertions and deletions, DNA polymerase slippage, which occurred during the repair of DNA strand breaks induced by the hypermutation process, may have led to these $\mathrm{V}$ gene modifications.

\section{MATERIALS AND METHODS}

\section{Synovial Mononuclear Cell Preparation}

The Institutional Review Board of North Shore University Hospital, Manhasset, NY, and Long Island Jewish Medical Center, New Hyde Park, NY, approved these studies. Synovial tissue was obtained at the time of surgery from 2 patients who fulfilled the American College of Rheumatology criteria for the diagnosis of RA (36). Each sample was minced and digested to obtain single cell suspensions as previously described (30). Mononuclear cells were isolated from these cell suspensions by density gradient centrifugation using Ficoll-Paque Plus (Amersham Pharmacia Biotech AB, Uppsala, Sweden). Isolated mononuclear cells were cryopreserved as viable cells in $10 \%$ dimethyl sulfoxide using a programmable cell-freezing machine (Thermo Forma, Marietta, OH, USA).

\section{RNA and cDNA Preparation}

Total RNA was extracted using Ultraspec RNA (Biotech Laboratories, Houston, TX, USA). One microgram of RNA was reverse transcribed to cDNA in a $20 \mu \mathrm{L}$ volume of $50 \mathrm{mM}$ Tris $\mathrm{HCl}(\mathrm{pH} 8.3$ ), $75 \mathrm{mM} \mathrm{KCl}, 3 \mathrm{mM} \mathrm{MgCl} 2,10 \mathrm{mM}$ dithiothreitol, containing $10 \mathrm{U} / \mu \mathrm{L}$ Moloney murine leukemia virus reverse transcriptase (Invitrogen, Carlsbad, CA, USA), 0.05 U/ $\mu \mathrm{L}$ RNase inhibitor (5 Prime 3 Prime, Boulder, CO, USA), and $1 \mu \mathrm{M}$ oligo dT primer. These reagent mixtures were incubated at $42{ }^{\circ} \mathrm{C}$ for $1 \mathrm{~h}$, heated to $65^{\circ} \mathrm{C}$ for $10 \mathrm{~min}$ to stop the reactions, and then diluted 5-fold with distilled water.

\section{Polymerase chain reaction (PCR) Amplification of Ig $V_{H}$ cDNA}

cDNA was amplified using $\mathrm{V}_{\mathrm{H}}$ family-specific framework region (FR) 1 sense primers or one of the sense $\mathrm{V}_{\mathrm{H}}$ family-specific leader primers paired with either a $C \mu, C \gamma$, or $C \alpha$ antisense primer (37). Cycling conditions for the FR1- $\mathrm{C}_{\mathrm{H}}$ primers were denaturation at $94{ }^{\circ} \mathrm{C}$ for $40 \mathrm{~s}$, annealing at $65^{\circ} \mathrm{C}$ for $45 \mathrm{~s}$, and extension at $72{ }^{\circ} \mathrm{C}$ for $40 \mathrm{~s}$, and repeated for 35 cycles. Cycling conditions for the $\mathrm{V}_{\mathrm{H}} \mathrm{L}-\mathrm{C}_{\mathrm{H}}$ primers were denaturation at $94{ }^{\circ} \mathrm{C}$ for $45 \mathrm{~s}$, annealing at $62{ }^{\circ} \mathrm{C}$ for $30 \mathrm{~s}$, and extension at $72{ }^{\circ} \mathrm{C}$ for $45 \mathrm{~s}$, and repeated for 35 cycles.

\section{Construction of cDNA Libraries and Sequencing of Selected Clones}

$\mathrm{V}_{\mathrm{H}^{-}}$specific DNA and $\mathrm{V}_{\mathrm{H}^{-}}, \mathrm{C}_{\mathrm{H}^{-}}$specific cDNA libraries were generated from PCR products as described (37). Each PCR product (10 ng) was ligated into pCR2.1 vector and transformed into TOP$10 \mathrm{~F}^{\prime}$ competent cells, using the TA cloning kit (Invitrogen, San Diego, CA, USA). EcoRI restriction enzyme-digested plasmid DNA fragments were analyzed on $1.0 \%$ agarose gels. Inserts with the correct size were sequenced. The obtained sequences were analyzed with MacVector and GeneWorks software programs (Oxford Molecular Group, Campbell, CA, USA). To determine the corresponding genomic DNA sequence, V BASE (MRC Centre for
Table 1. Frequency of insertion and deletion detected in synovial tissue $\mathrm{V}_{\mathrm{H}}$ clones

\begin{tabular}{lcccc} 
& $\lg M(206)^{a}$ & $\operatorname{lgG}(263)^{a}$ & $\operatorname{lgA}(276)^{a}$ & ${\text { Total }(745)^{a}}^{a}$ \\
\hline Insertion & $0 \%$ & $0.76 \%(2)^{b}$ & $1.45 \%(4)$ & $0.81 \%(6)$ \\
Deletion & $0 \%$ & $1.14 \%(3)$ & $0.36 \%(1)$ & $0.54 \%(4)$ \\
Total & $0 \%$ & $1.90 \%(5)$ & $1.81 \%(5)$ & $1.34 \%(10)$ \\
\hline
\end{tabular}

a Number of clones sequenced.

bNumber of clones exhibiting either insertion or deletion is found within the parentheses.

Protein Engineering, Cambridge, UK, http://www. mrccpe.cam.ac.uk/imt-doc/restricted/ok.html) was used. All $V_{H}$ gene sequences discussed in this study have been entered in GenBank under accession numbers (AY392842-AY393208, AY393218AY393595).

\section{Calculation of Minimum Free Energy of Adjacent DNA Sequences}

The calculation of minimum free energy is based on the dynamic programming algorithm $(38,39)$ using the DNA parameters provided by SantaLucia Jr (40), which include those for non-canonical base pairing, for example, G-T (41). The calculations were made using Vienna RNA Package Web site (http://www.tbi.univie.ac. at/ ivo/RNA/).

\section{RESULTS}

\section{Nucleotide Insertions}

We analyzed cDNA sequences of 745 clones derived from synovial tissues of 2 RA patients (RA702 and RA129). Two hundred six of these clones were of the IgM isotype, 263 of the IgG isotype, and 276 of the IgA isotype. Of the 745 clones, $6(0.81 \%)$ exhibited $V_{H}$ sequence changes consistent with nucleotide insertions (Table 1). Insertions were found in clones expressing several different $V_{H}$ families $\left(\mathrm{V}_{\mathrm{H}} 1,2,3,4\right.$, and 6$)$. Each of these clones contained isotype switched $\mathrm{C}_{\mathrm{H}}(2 \gamma$ and $4 \alpha$ constant regions; Table 1$)$.

All nucleotide insertions occurred as multiples of 3 base pairs ( 3 to 12 bp; boxed on Figure 1) and none generated a stop codon; therefore, they maintained the original reading frame and had the potential to code an intact receptor. These findings are not unexpected because our analyses were performed on cDNA. In general, these inserted nucleotides resembled duplications of an immediately adjacent nucleotide segment. In 2 cases, the inserted duplication was an exact replica of the germline sequence (clones RA702-A6-27 and RA129-G1-54, see circled sequences on Figure $1 \mathrm{~A}$ and $1 \mathrm{~B})$. In the other 4 instances, these apparent duplications differed from the germline at individual nucleotides; these nucleotide differences ranged from 1 to 4 per segment (for example, clones RA702-A4-28, RA129-A6-23, RA702-A3-27, and RA702-G2-10; circled on Figure 1C through 1F).

\section{Nucleotide Deletions}

In addition to insertions, 4 of the original 745 clones exhibited $\mathrm{V}_{\mathrm{H}}$ sequence changes consistent with nucleotide deletions $(0.54 \%)$. 


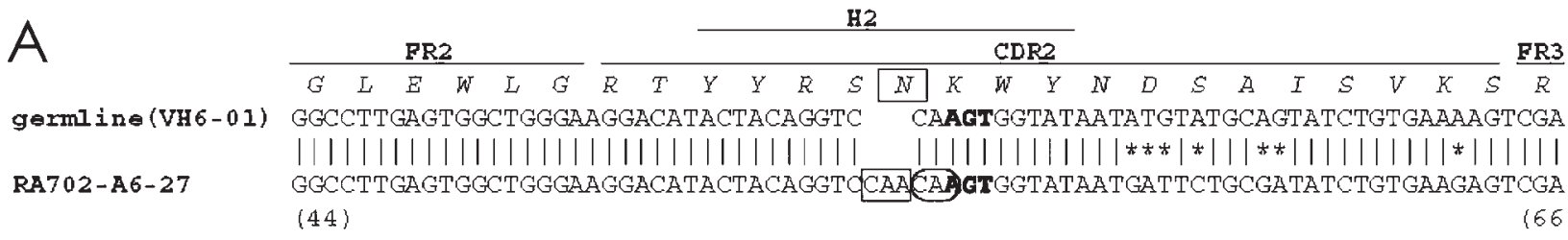

B

germline (VH1-f)

RA129-G1-54

$C$

germl ine (VH 4b)

RA702-A4-28

D

germline (VH6-01)

RA129-A6-23

E

germline $(\mathrm{VH} 3-30)$

RA702-A3-27

H]

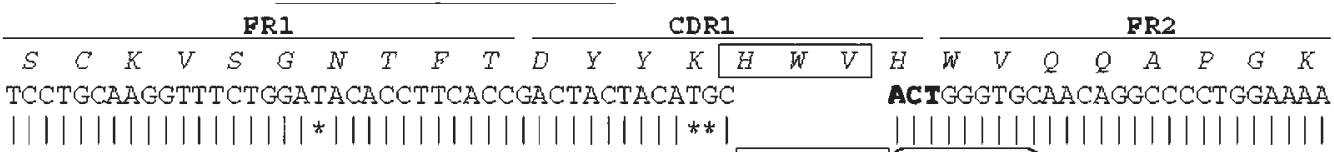
TCCTGCAAGGTTTCTGGAAACACCTTCACCGACTACTACAAACACTGGGTGC TCTGGGTGDAACAGGCCCCTGGAAA (21)

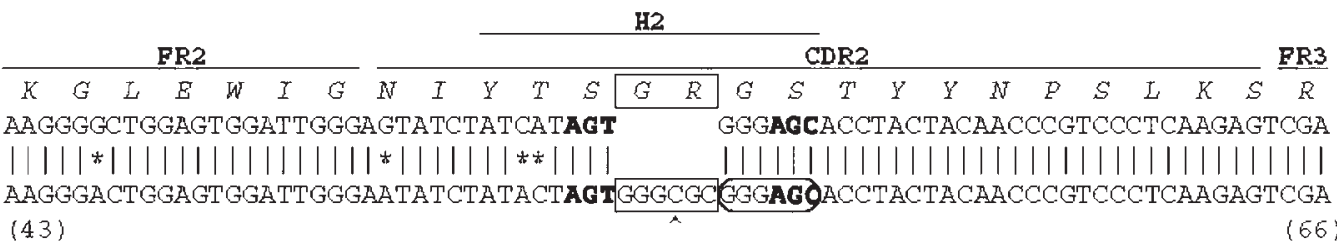
(43)

(65)

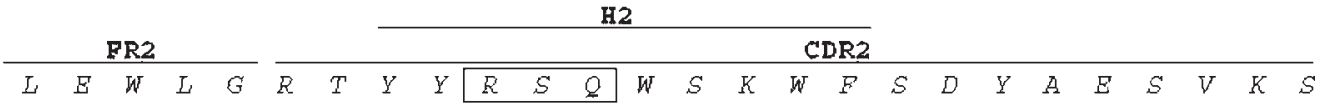

CTTGAGTGGCTGGGAAGGACATACTACA GGTCCAAGTGGTATAATGATTATGCAGTATCTGTGAAAAGT ||||||||||||||||||||||||||||| |||||||||||||*||*||||||||||||*|||||||||||||* CTTGA GTGGCTGGGAAGGACATACTACA GGTCCCAGTGGTCCAAGTGGTTTAGTGATTATGCAGAATCTGTGAAAAGC (45)

H1

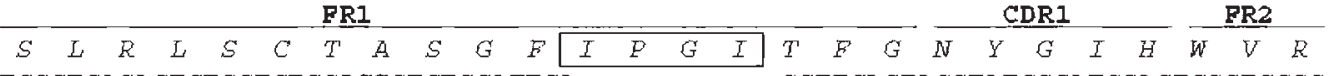

TCCCTGAGACTCTCCTGTGCAGCGTCTGGATTCA CCTTCAGTAGCTATGGCATGCACTGGGTCCGC |||||||||||||||||**||||||||||*|||| |||||*|*|**||||||||*|||||||||||* TCCCTGAGACTCTCCTGCACAGEGTTGGGTTCATCCTGGAATCACCTTCGGCAATTATGGCATACACTGGGTCCGA (17)

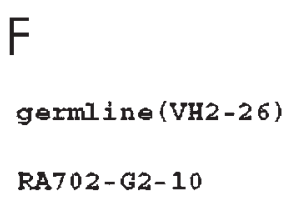

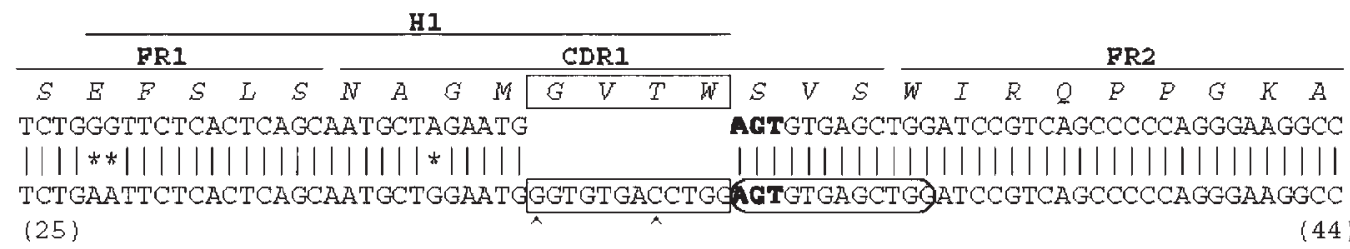

Figure 1. cDNA sequences of $V_{H}$ clones with nucleotide insertions. Sequences of 6 clones with nucleotide insertions (A to F) are displayed with their corresponding germline sequences. CDR, FR, and $\mathrm{H}$ regions are marked. Amino acid sequences are also indicated. The inserted nucleotides and amino acids are boxed, and the duplicated sequences are circled. Mismatches between the most similar germline genes and the identified rearranged $V_{H} D J_{H}$ genes are shown with *. Mutations within duplicated sequences are indicated by $\wedge$. AGY sequences adjacent to the insertions are shown in bold font. Amino acid sequence numbers of the deduced $V$ region protein are shown in parentheses.

Three of the clones with deletions expressed $\gamma$ constant regions and 1 clone expressed an $\alpha$ constant region (Table 1). Figure 2 shows that these deletions varied in length from 3 to 18 nucleotides (boxed in Figure 2). Like the insertions, each deleted sequence comprised a multiple of 3 nucleotides, and therefore could code a productive rearrangement.

\section{Location of the Insertions and Deletions}

The insertions and deletions detected in these synovial B cell cDNA samples were not randomly distributed along $\mathrm{V}_{\mathrm{H}}$. Most insertions occurred in the hypervariable regions (Figures 1 and 2). RA702-A3-27 (see Figure 1E) exhibited an insertion just upstream of the FR1-complementarity determining region (CDR)1 junction, whereas RA129-G1-54 and RA702-G2-10 had insertions in CDR1 (see Figure 1B and 1F) and RA702-A6-27, RA702-A4-28, RA129A6-23 contain insertions in CDR2 (see Figure 1A, 1C, and 1D).

Three of the 4 deletions were located either completely or predominantly within CDRs (see Figure 2). Clone RA129-A1-6 exhibited a 3-bp deletion at the junction of FR1 and CDR1 (see Figure 2A), whereas clones RA129-G1-88 and RA129-G2-48, with 3-bp 


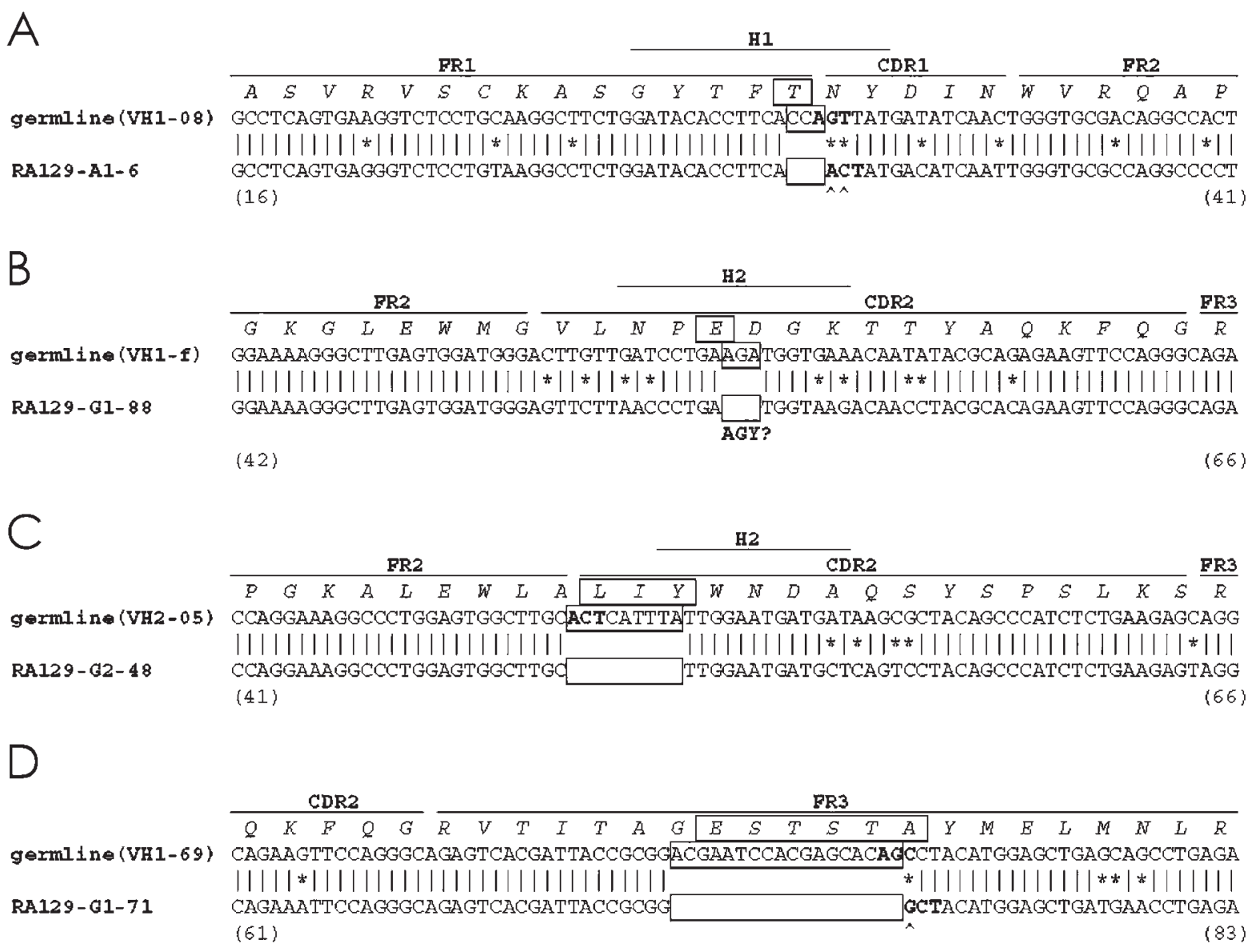

Figure 2. cDNA sequences of $V_{H}$ clones with nucleotide deletions. Sequences of 4 clones with nucleotide deletions (A-D) are displayed with their corresponding germline sequences. CDR, FR, and $\mathrm{H}$ regions, and amino acid sequences are indicated as in Figure 1 . The deleted sequences and amino acids are boxed ( $\square$ ). AGY? underlies an AGA site that is similar to a canonical AGY sequence.

and 6-bp deletions, respectively, had losses in CDR2 (see Figure $2 \mathrm{~B}$ and $2 \mathrm{C}$ ). The one exception was the 18-bp nucleotide deletion identified in the clone RA129-G1-71, which was located in FR3 region (see Figure 2D).

Two schemes are used to describe the hypervariable and likely antigen-contact regions of the $\mathrm{V}_{\mathrm{H}}$ segment. The Kabat system (CDR1, CDR2, and CDR3 [42]) is based on sequence variability, and the Chothia system (H1, H2, and H3 [43]) is based on the locations of structural loops. Although these regions are very similar in location, they do not always overlap. Notably, 5 of 6 clones with insertions are mapped to the $\mathrm{H} 1$ and $\mathrm{H} 2$ regions (Figures 1 and 3 ). Furthermore, the 3 insertions that were identified in CDR2, a region of 48 to 57 nucleotides in length, all clustered in the $\mathrm{H} 2$ region, a much more restricted area of only 15 to 24 nucleotides at the 5' end of CDR2 (Figure 3). In agreement with the insertions, all 3 of the CDR-associated deletions clustered in the $\mathrm{H} 1$ and $\mathrm{H} 2$ regions (Figures 2 and 3 ).

\section{Nucleotide Motifs Located At or Near Insertions and Deletions}

The inserted sequences were highly homologous or identical to short sequences close to (either upstream or downstream from) the insertion site (Figure 4A-shaded in gray and black, discon- tinuous in some instances). Other investigators have referred to these sequences as "misalignment feet" (32-35). In clones with deletions, similar "feet" can be identified next to the deletion sites (Figure 4B-shaded in gray and black, discontinuous in some instances).

All of the clones contained palindromic sequences within the sites of insertion (see Figure 1). The lengths of these palindromes and their degrees of complementarity varied from 3 to 7 nucleotides. Examples of palindromic sequences in 2 clones with an insertion are depicted in Figure 4A. The palindromes were either primary, because they existed in the $\mathrm{V}_{\mathrm{H}}$ germline sequence, or secondary, being generated somatically by mutation (data not shown). Similarly in each of the clones with deletions, palindromic sequences, with lengths of 3 to 21 nucleotides, existed within the deleted sequences (see examples in Figure 4B). These palindromes could form stem-loop structures with varying stretches of complementarity and with varying free energies of association (see Figure $4 \mathrm{~A}$ and $4 \mathrm{~B}$ ). In 7 of 10 instances, the minimum free energies (calculated as $\mathrm{kcal} / \mathrm{mol}$ ) differed between the proposed stem loops of the DNA strands, suggesting that the duration of structural stability of the loops in the 2 strands could vary.

Finally, AGY trinucleotides $(44,45)$ are located adjacent to all but 1 of the insertions and deletions detected (see bolded portions of 


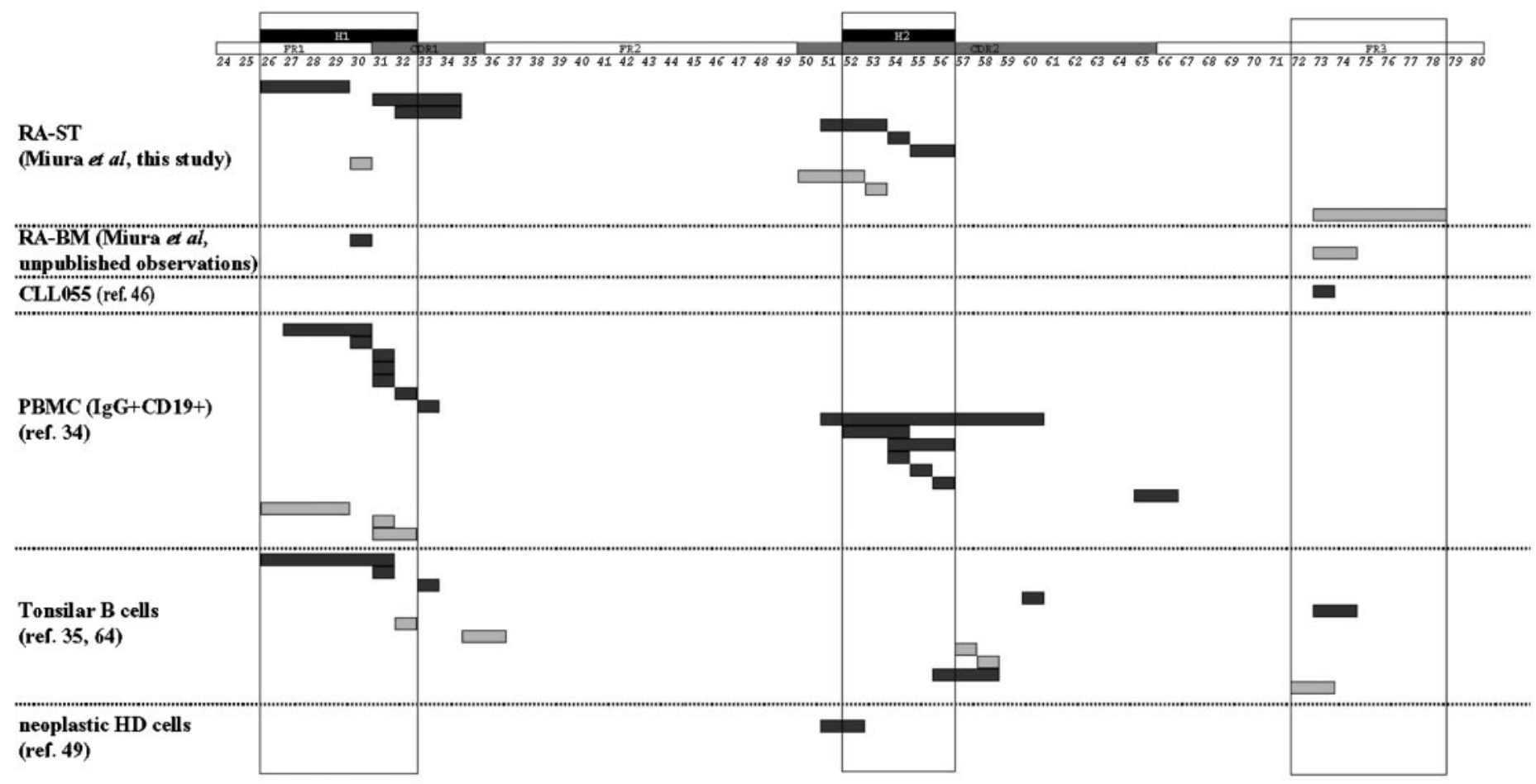

insertion $\square$ deletion

Figure 3. Majority of insertions and deletions map to the $\mathrm{H} 1$ and $\mathrm{H} 2$ regions. Diagrammatic representation of the nucleotide insertions (shaded dark) and deletions (shaded light) identified in CDNA clones isolated from synovial tissue of patients with RA from this study (RA-ST), from bone marrow of a patient with RA (RA-BM), from peripheral B cells of a patient with chronic lymphocytic leukemia (CLL055; [46]), from PBMC (34), from tonsillar B-cell subsets $(35,65)$, and from the neoplastic cells of patients with Hodgkin's disease (49). CDR, FR, and H regions are boxed. Numbers indicate the positions of corresponding amino acids.

Figures 1 and 2). The only clone that does not display an accurate AGY motif at or in the site of insertion or deletion is RA129-G1-88 (see Figure 2B). An AGA is located at the deletion site in this clone.

\section{Verification}

To assure that the inserted and deleted sequences were not in vitro artifacts of either PCR or cloning, we designed HCDR3-specific anti-sense primers for a clone containing an insertion (RA702-G210) and a primer expressing a deletion (RA129-G2-48) to search for these variants in the original cDNA samples. Because both of these specific primers are located at the $3^{\prime}$ end of the HCDR3, the $5^{\prime}$ portion of each $\mathrm{D}$ segment and the unique nucleotides at the $\mathrm{V}_{\mathrm{H}^{-}} \mathrm{D}$ junctions serve as "signature sequences" (highlighted on Figure 5) to assure the identity of the respective clones.

Using the original cDNA as templates, PCR were performed with these anti-sense primers and the appropriate $V_{H}$ FR1 familyspecific primers. PCR products were cloned and sequenced to verify independently the existence of the inserted and deleted nucleotide sequences. Using the RA702-G2-10 specific primer set, 31 clones were sequenced; all were identical to each other and to clone RA702-G2-10. This identity included the 12-bp insertion and the 5' HCDR3 signature sequence (see Figures 1 and 5). Likewise, using the RA129-G2-48 specific primer, 6 clones were sequenced and each contained the identical nucleotide deletion and the HCDR3 signature sequence of clone RA129-G2-48 (see Figures 2 and 5). These results strongly support the conclusion that the insertions and deletions detected in this study were not technical artifacts, and that these $\mathrm{V}_{\mathrm{H}}$ variants were present in clonally active and possibly expanded B cells.

Finally, to rule out the possibility that the inserted or deleted sequences were part of the germline gene complement of these patients, we examined $6 \mathrm{~V}_{\mathrm{H}^{2}}$-26 gene-expressing clones from patient RA702 (3 IgM, 2 IgG, and $1 \mathrm{IgA}$ ) and $58 \mathrm{~V}_{\mathrm{H}^{2}}$-05 geneexpressing clones $(8 \mathrm{IgM}, 28 \mathrm{IgG}$, and $28 \mathrm{IgA})$ from patient RA129. None of these clones contained the nucleotide additions or deletions observed in clones RA129-G2-48 and RA702-G2-10 (not shown). These data indicate that the inserted and deleted portions identified in our study were generated somatically and did not represent polymorphic variants of the $\mathrm{V}_{\mathrm{H}^{2}} 2-26$ and $\mathrm{V}_{\mathrm{H}} 2-05$ genes.

\section{DISCUSSION}

In this study, we documented the occurrence of nucleotide insertions and deletions (frequency 1.34\%) in Ig $\mathrm{V}_{\mathrm{H}}$ genes expressed by B lymphocytes in the synovial tissues of patients with RA. This frequency is consistent with other reports describing insertions and deletions in normal $(34,35)$ and neoplastic (16) human B cells. Because the frequency of the changes that occur in synovial tissue 
A
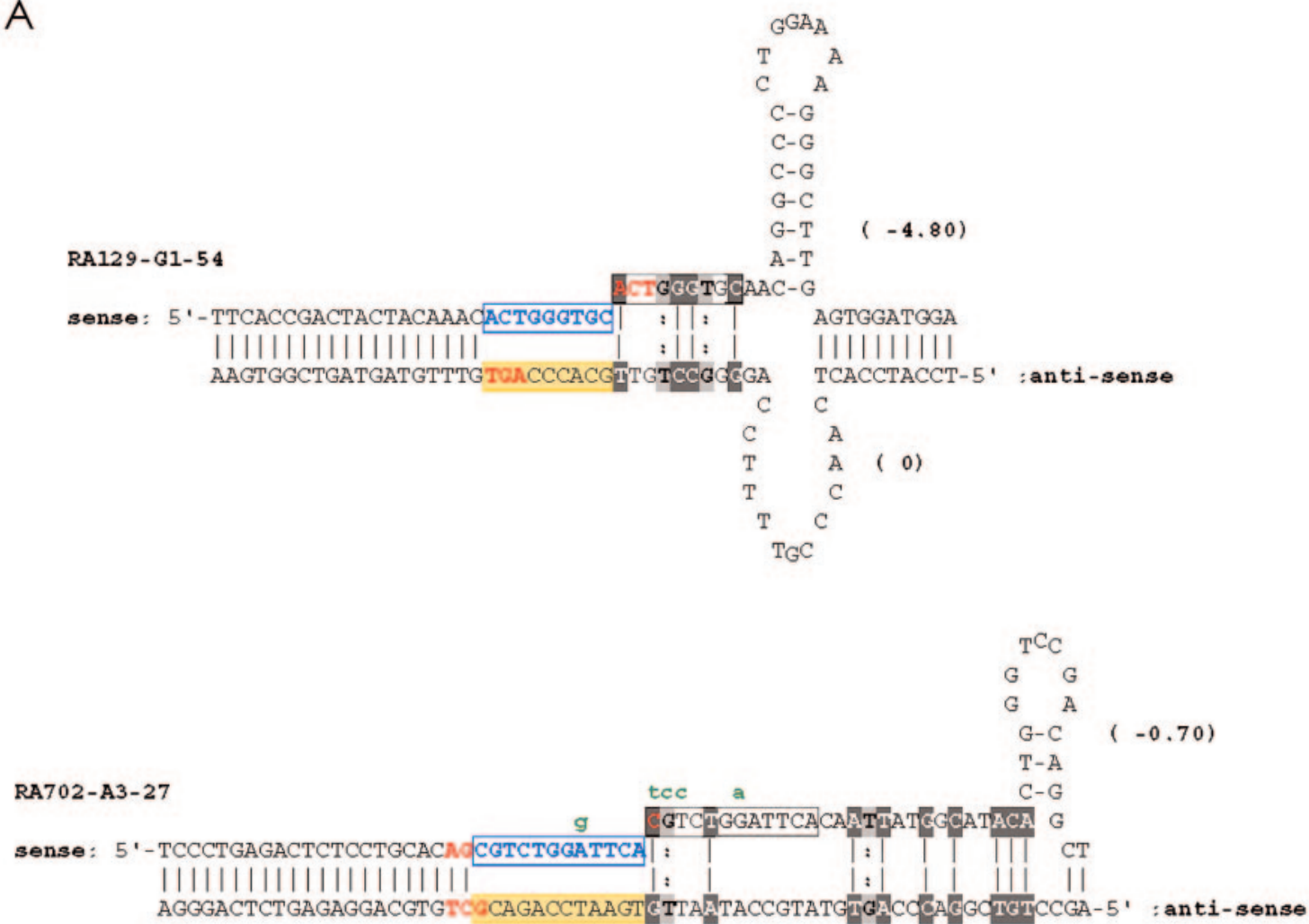

B
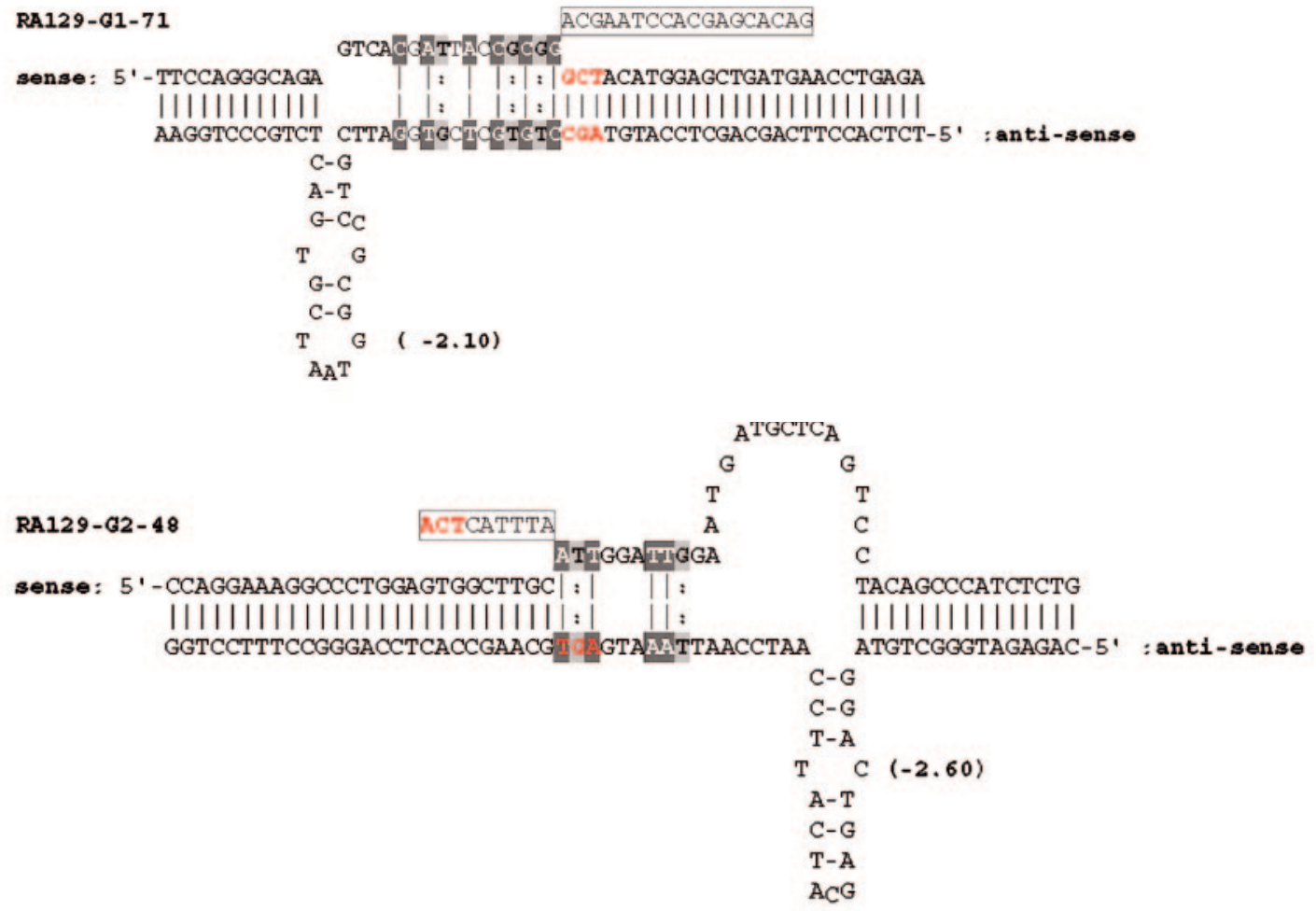

Figure 4. Secondary structure of DNA at sites of insertion and deletion. A: AGY motifs at proposed sites of DNA breaks are shown in red, sequences used as templates in yellow shade, and duplicated sequences in blue boxes. Misaligned feet sequences are discontinuous and indicated by black and gray shading. (A-T and G-C are shown in reverse text connected by a solid line; G-T is shown in light gray connected by a dotted line). Putative mutations introduced after duplication are shown in green. The minimum free energies in $\mathrm{kcal} / \mathrm{mol}$ are given in parentheses. B: As in A, except that the deleted sequences are boxed. 


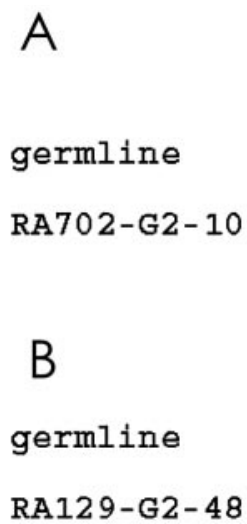

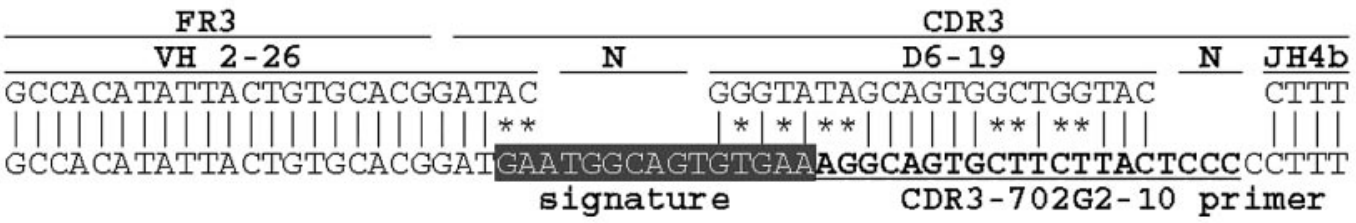

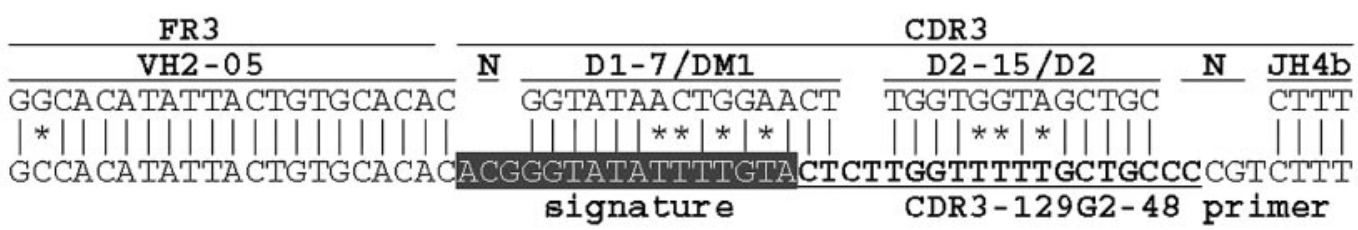

Figure 5. Primers used to verify the presence of insertions and deletions in original cDNA. Primers used to verify the insertion identified in clone RA702G2-10 (A) and in clone RA129-G2-48 (B) are underlined. The signature sequences are shown in shaded reverse text.

B cells is so similar to that of normal and neoplastic B cells, it is likely that these insertions and deletions represent the sequellae of a normal B-cell diversification process and not one that is unique to RA synovia or to treatments that these patients received. In addition, these $\mathrm{V}$ gene modifications were generated somatically and were not natural germline polymorphisms because they could not be found in other clones using the same $\mathrm{V}_{\mathrm{H}}$ genes from the same patients. Furthermore, the insertions and deletions were not artifacts because HCDR3-specific PCR identified the same insertion or deletion, with the identical HCDR3 signature sequences, in each instance tested.

Nine of 10 DNA insertions and deletions identified (see Figures 1 and 2) were located in $H$ regions of the $V_{H}$ gene as defined by Chothia (43). When we combine the 3 most relevant studies (34, 35 , and this report), 37 of $43(86 \%)$ of the insertions or deletions localize to hypervariable loops of the $\mathrm{V}_{\mathrm{H}}$ and $\mathrm{V}_{\mathrm{L}}$ genes (see Figure 3).

Amino acid position 73 in FR3 appears to be a hot spot for mutation (42). One of our clones contained a deletion located in FR3 (RA129 G1-71; see Figure 2D). We have also identified in this region a deletion in a cDNA clone from RA bone marrow cells (GenBank Nr AY393645), and an insertion in a clone from a patient with B-cell chronic lymphocytic leukemia (CLL055 [46], as others have found in tonsilar B cells [35]; see Figure 3). Therefore, changes in the structural antigen binding loops of the $\mathrm{V}$ gene or in the area of FR3 surrounding position 73 may be more frequent (see below), more tolerable, or more advantageous for B cell selection than changes in other portions of $\mathrm{V}_{\mathrm{H}}$. Significant genetic changes in other FR areas might lead to a structurally impaired and dysfunctional B-cell antigen receptor that would not be consistent with surface expression and B-cell survival (47).

\section{Potential Mechanisms of Nucleotide Insertion and Deletion}

The mechanisms responsible for $\mathrm{Ig} \mathrm{V}$ gene insertions and deletions have not been conclusively defined. DNA polymerase slippage occurring during DNA synthesis is a potential mechanism (35). In this model, a short stretch of DNA ("foot") that is complementary to a sequence upstream or downstream from its normal partner sequence on the daughter strand is a requisite feature. It has been suggested that this foot can become misaligned with its upstream partner to result in a nucleotide insertion or with its downstream partner to lead to a deletion $(34,35)$. In our cases, such feet can be found near the insertion or deletion sites, although the complementary nucleotides are often discontinuous and can span larger distances than originally described (see Figures 1 and 2). They also take into account noncanonical interactions such as G-T base pairing, which can form in double stranded regions of ssDNA (48).

Alternatively, nucleotide insertion/deletions could occur by a similar mechanism at the time of DNA repair during the somatic hypermutation process. There are several reasons to consider that DNA breaks, which are essential for somatic hypermutation, may be involved in these processes-based on our data and that reported previously by others $(49,50)$.

First, these insertions and deletions occurred only in clones that had undergone an isotype class switch; none were found in clones expressing $\mu \mathrm{H}$ chains. Furthermore, the level of $\mathrm{V}$ gene mutation was much greater among the non-IgM than among the IgMexpressing clones (IgM: 2.56\%; IgG: 7.09\%; IgA: 6.93\%; Table 2). These findings suggest a close relationship between DNA insertion/ deletion and isotype switching and somatic hypermutation.

Second, virtually all of these changes were detected in CDRs or in areas of the FR that are relatively variable and are frequent targets of somatic mutation.

Third, in 9 of 10 cases, a trinucleotide hot spot (AGY motif) was found at or in the site of the insertion or deletion. In a case in which this was not found (RA129-G1-88; see Figure 2B), there is an AGA at the site of the deletion that differs by only 1 nucleotide from the canonical AGY. The almost obligate finding of this

Table 2. Frequency of $\lg V_{H}$ gene point mutations detected in synovial tissue $\mathrm{V}_{\mathrm{H}}$ clones

\begin{tabular}{cccc} 
& $\lg M(92)^{a}$ & $\lg (138)^{a}$ & $\operatorname{lgA}(276)^{a}$ \\
\hline Point mutations & $2.56 \%$ & $7.90 \%$ & $6.93 \%$ \\
\hline
\end{tabular}

a Number of clones sequenced. 
hotspot motif at or in the site of the insertion or deletion is especially relevant because of the recent suggestion that the somatic hypermutation process is initiated by activation-induced cytidine deaminase (AID [51,52]) by deamination of cytidine (C), yielding uridine. This uridine substitution can lead to an abasic site in the DNA strand that is then susceptible to cleavage (53). Thus, AID initiates DNA breaks at germinal centers pairs. In all of our insertions/deletions, the canonical AGY or the variant AGA motif (RA129-G1-88) could represent targets for AID-mediated cleavage of the complementary strand at the 2nd nucleotide $(\mathrm{C})$ in the motif. In 7 of 10 instances, the pyrimidine $C$ is a component of the AGY motif on the sense strand that is located at/near the insertion/deletion site. The involvement of AID in the deletion process is supported by its proposed role in the deletions required for class switch recombination (54).

Finally, we identified stretches of DNA ("feet") on the nicked strand that are complementary to sequences upstream or downstream of the normal partner sequence and also palindromic sequences next to or upstream of deleted or inserted sequences (Figures 1, 2, 4). It is conceivable that following ds- (55) or ss- (56) DNA breaks, presumably involving AID, these palindromes form DNA hairpin loops that retract or stretch the broken DNA strand. When the minimum free energies developed in the loops by these palindromes are calculated (see Figure $4 \mathrm{~A}$ and $4 \mathrm{~B}$ ), retraction of the nicked strand into a transient stem loop structure is often more stable than that of the daughter strand. This would facilitate misalignment of the DNA feet with inappropriate, complementary sequences on the daughter strand, resulting in insertions. Similar examples exist for the clones with deletions (see Figure 4B). In these cases, the hairpins with the greater energies on the daughter strands could preferentially retract this strand and maintain the stem loop structure long enough to allow the feet to misalign to downstream complementary pseudo-partners, leading to DNA deletions. These minimum free energy differences between the 2 strands are obvious in 7 of 10 insertion/deletion cases (data not shown).

We frequently found somatic mutations within the adjacent palindromic sequences and occasionally in the "feet." Thus, mutation may lead to the formation of nucleotide sequences that provide the opportunity for the proposed misalignment reaction and resulting insertion or deletion. Such mutations and secondary events could account for the deletion detected in clone RA129-G1-88 in which the germline sequence does not contain the expected AGY hot spot motif at the site of modification (see Figure 2B).

\section{Potential Relevance of Nucleotide Insertion/Deletion in RA}

Nucleotide insertion/deletion offers an additional mechanism for the generation of antigen-binding diversity within B lymphocyte populations (57). Because all sequences exhibiting insertions or deletions could be amplified directly from cDNA of synovial tissue B cells, it is likely that the B cells expressing these altered V genes were transcriptionally active and clonally expanded. Clonal expansion requires the variant B-cell antigen receptor to have an adequate affinity for an antigen found within the joint. In addition, rescue from apoptosis requires such reactivity. Because in RA Ig V gene diversification can take place in a microenvironment that does not normally support B cell maturation (the hypertrophied and inflamed rheumatoid synovium), the nonphysiologic nature of this environment could lead to an inefficient maintenance of tolerance. If self-antigen led to rescue from apoptosis, then any diversification event could potentially add to the autoantibody response in RA, as is the case for anti-dsDNA antibodies in murine SLE $(58,59)$. Alternatively, if the rescuing antigen is a component of the immune or inflammatory systems, such variants could potentially down-regulate these systems and diminish joint destruction. IgG would satisfy both of these scenarios; it can be an autoantigen for RF $(18,19)$, and it can be the target of antibody-mediated $(60-62)$ and possibly T cell-mediated $(63,64)$ regulatory responses during normal immune reactions.

\section{ACKNOWLEDGMENTS}

These studies were supported in part by US PHS grant AI 10811 from the NIH NIAID, by the Leonard Wagner Autoimmunity Research Fund, The Jerry and Cecile Shore Fund for Immunologic Research, and the Richard and Nancy Leeds Fund of North Shore Univ. Hospital. The authors greatly appreciate the editorial help provided by Dr. Ming-der Chang in the preparation of this manuscript. This article was presented in part at the 65th Annual Meeting of The American College of Rheumatology, Boston, MA, November 14, 2001.

Address correspondence and reprint requests to Nicholas Chiorazzi, North Shore-LIJ Research Institute, 350 Community Drive, Manhasset, NY 11030. Phone: 516-562-1085; fax: 516-562-1022; e-mail: nchizzi@nshs.edu.

Submitted June 12, 2003; accepted for publication August 21, 2003.

\section{REFERENCES}

1. Alt FW, Oltz EM, Young F, Gorman J, Taccioli G, Chen J. (1992) VDJ recombination. Immunol. Today 13:306-14.

2. Meffre E, Casellas R, Nussenzweig MC. (2000) Antibody regulation of B cell development. Nature Immunol. 1:379-85.

3. Gay D, Saunders T, Camper S, Weigert M. (1993) Receptor editing: an approach by autoreactive B cells to escape tolerance. J. Exp. Med. 177:999-1008.

4. Radic MZ, Erikson J, Litwin S, Weigert M. (1993) B lymphocytes may escape tolerance by revising their antigen receptors. J. Exp. Med. 177:1 165-73.

5. Tiegs SL, Russell DM, Nemazee D. (1993) Receptor editing in self-reactive bone marrow B cells. J. Exp. Med. 177:1009-20.

6. Kelsoe G. (1996) Life and death in germinal centers (redux). Immunity 4:107-11.

7. de Vinuesa CG et al. (2000) Germinal centers without T cells. J. Exp. Med. 191: 485-94.

8. Weller S et al. 2001. CD40-CD40L independent lg gene hypermutation suggests a second B cell diversification pathway in humans. Proc. Natl. Acad. Sci. U.S.A. 98:1166-70.

9. William J, Euler C, Christensen S, Shlomchik MJ. (2002) Evolution of autoantibody responses via somatic hypermutation outside of germinal centers. Science 297: 2066-70

10. Wilson PC, Wilson K, Liu Y-J, Banchereau J, Pascual V, Capra JD. (2000) Receptor revision of immunoglobulin heavy chain variable region genes in normal human B lymphocytes. J. Exp. Med. 191:1881-94.

11. Kleinfield R, Hardy RR, Tarlinton D, Dangl J, Herzenberg LA, Weigert M. (1986) Recombination between an expressed immunoglobulin heavy-chain gene and a germline variable gene segment in a Ly 1+ B-cell lymphoma. Nature 322:843-6.

12. Reth M, Gehrmann P, Petrac E, Wiese P. (1986) A novel VH to VHDJH joining mechanism in heavy-chain-negative (null) pre-B cells results in heavy-chain production. Nature 322:840-2.

13. Covey LR, Ferrier P, Alt FW. (1990) VH to VHDJH rearrangement is mediated by the internal $\mathrm{VH}$ heptamer. Int. Immunol. 2:579-83.

14. de Wildt RM, Hoet RMA, van Venrooij WJ, Tomlinson IM, Winter G. (1999) Analysis 
of heavy and light chain pairings indicates that receptor editing shapes the human antibody repertoire. J. Mol. Biol. 285:895-901.

15. Wilson P, Liu YJ, Banchereau J, Capra JD, Pascual V. (1998) Amino acid insertions and deletions contribute to diversify the human Ig repertoire. Immunol. Rev. 162:143-51.

16. Goossens T Klein U, Kuppers R. (1998) Frequent occurrence of deletions and duplications during somatic hypermutation: implications for oncogene translocations and heavy chain disease. Proc. Natl. Acad. Sci. U.S.A. 95:2463-8.

17. Harris Jr ED. (1990) Rheumatoid arthritis. Pathophysiology and implications for therapy. N. Engl. J. Med. 322:1277-89.

18. Waaler E. (1940) On the occurrence of a factor in human serum activating the specific agglutination of sheep blood corpuscles. Acta Pathol. Microbiol. Scand. 17:172-88.

19. Rose HM, Ragan C, Pearce E, Lipman MO. (1948) Differential agglutination of normal and sensitized sheep erythrocytes by sera of patients with rheumatoid arthritis. Proc. Soc. Exp. Biol. Med. 68:1-6.

20. Clague RB, Morgan K, Reynolds I, Williams HJ. (1994) The prevalence of serum IgG antibodies to type II collagen in American patients with rheumatoid arthritis. Br. J. Rheumatol. 33:336-8.

21. Schellekens GA, de Jong BA, van den Hoogen FH, van de Putte LB, van Venrooij WJ. (1998) Citrulline is an essential constituent of antigenic determinants recognized by rheumatoid arthritis-specific autoantibodies. J. Clin. Invest. 101:273-81.

22. Phillips PE. (1988) Evidence implicating infectious agents in rheumatoid arthritis and juvenile rheumatoid arthritis. Clin. Exp. Rheumatol 6:87-94.

23. Kouri T et al. (1990) Antibodies to synthetic peptides from Epstein-Barr nuclear antigen-1 in sera of patients with early rheumatoid arthritis and in preillness sera. J. Rheumatol. 17:1442-9.

24. Hajeer AH, MacGregor AJ, Rigby AS, Ollier WE, Carthy D, Silman AJ. (1994) Influence of previous exposure to human parvovirus B19 infection in explaining susceptibility to rheumatoid arthritis: an analysis of disease discordant twin pairs. Ann. Rheum. Dis. 53:137-9.

25. Kouskoff V, Korganow AS, Duchatelle V, Degott C, Benoist C, Mathis D. (1996) Organ-specific disease provoked by systemic autoimmunity. Cell 87:81 1-22.

26. Korganow AS et al. (1999) From systemic T cell self-reactivity to organ-specific autoimmune disease via immunoglobulins. Immunity 10:451-61.

27. Maccioni $M$ et al. (2002) Arthritogenic monoclonal antibodies from $K / B \times N$ mice. J. Exp. Med. 195:1071-7.

28. Bridges Jr SL, Lee SK, Koopman WJ, Schroeder Jr HW. (1993) Analysis of immunoglobulin gamma heavy chain expression in synovial tissue of a patient with rheumatoid arthritis. Arthritis Rheum. 36:631-41.

29. Schroder AE, Greiner A, Seyfert C, Berek C. (1996) Differentiation of B cells in the nonlymphoid tissue of the synovial membrane of patients with rheumatoid arthritis. Proc. Natl. Acad. Sci. U.S.A. 93:221-5.

30. Itoh K, Chiorazzi N. (2000) Clonal expansion is a characteristic feature of the B-cell repertoire of patients with rheumatoid arthritis. Arthritis Res. 2:50-8.

31. Randen I, Mellbye OJ, Forre O, Natvig JB. (1995) The identification of germinal centres and follicular dendritic cell networks in rheumatoid synovial tissue. Scand. J. Immunol. 41:481-6.

32. Streisinger $G$ et al. (1966) Frameshift mutations and the genetic code. Cold Spring Harb. Symp. Quant. Biol. 31:77-84.

33. Ripley LS. (1990) Frameshift mutation: determinants of specificity. Annu. Rev. Genet. 24:189-213.

34. de Wildt RM, van Venrooij WJ, Winter G, Hoet RM, Tomlinson IM. (1999) Somatic insertions and deletions shape the human antibody repertoire. J. Mol. Biol. 294: 701-10.

35. Wilson PC et al. (1998) Somatic hypermutation introduces insertions and deletions into immunoglobulin $\vee$ genes. J. Exp. Med. 187:59-70.

36. Arnett FC et al. (1988) The American Rheumatism Assn. 1987 revised criteria for the classification of rheumatoid arthritis. Arthritis Rheum. 31:315-24.

37. Fais $\mathrm{F}$ et al. (1998) Chronic lymphocytic leukemia B cells express restricted sets of mutated and unmutated antigen receptors. J Clin Invest 102:1515-25.

38. Walter AE et al. (1994) Coaxial stacking of helixes enhances binding of oligoribonucleotides and improves predictions of RNA folding. Proc. Natl. Acad. Sci. U.S.A. 91:9218-22.

39. Mathews DH, Sabina J, Zuker M, Turner DH. (1999) Expanded sequence dependence of thermodynamic parameters improves prediction of RNA secondary structure. J. Mol. Biol. 288:911-40.

40. SantaLucia Jr J. (1998) A unified view of polymer, dumbbell, and oligonucleotide DNA nearest-neighbor thermodynamics. Proc. Natl. Acad. Sci. U.S.A. 95:1 460-5.
41. Allawi HT, SantaLucia Jr J. (1998) NMR solution structure of a DNA dodecamer containing single G*T mismatches. Nucleic Acids Res. 26:4925-34

42. Johnson G. Wu TT. (2000) Kabat database and its applications: 30 years after the first variability plot. Nucleic Acids Res. 28:214-8.

43. Chothia $\mathrm{C}$ et al. (1992) Structural repertoire of the human VH segments. J. Mol. Biol. 227:799-817.

44. Smith DS, Creadon G, Jena PK, Portanova JP, Kotzin BL, Wysocki LJ. (1996) Diand trinucleotide target preferences of somatic mutagenesis in normal and autoreactive B cells. J. Immunol. 156:2642-52.

45. Wagner SD, Milstein C, Neuberger MS. (1995) Codon bias targets mutation. Nature 376:732

46. Hashimoto $S$ et al. (1995) Somatic diversification and selection of immunoglobulin heavy and light chain variable region genes in IgG+ CD5+ chronic lymphocytic leukemia B cells. J. Exp. Med. 181:1507-17.

47. Lam KP, Kuhn R, Rajewsky K. (1997) In vivo ablation of surface immunoglobulin on mature $B$ cells by inducible gene targeting results in rapid cell death. Cell 90:1073-83.

48. Lewin B. (1994) Single-stranded nucleic acids may have secondary structure. In: Genes V. Lewin B (ed.) Oxford Univ. Press, Oxford, pp. 113-9.

49. Kuppers R, Goossens T, Klein U. (1999) The role of somatic hypermutation in the generation of deletions and duplications in human Ig $\mathrm{V}$ region genes and chromosomal translocations. Curr. Top Microbiol. Immunol. 246:193-8.

50. Papavasiliou FN, Schatz DG. (2000) Cell-cycle-regulated DNA doublestrand breaks in somatic hypermutation of immunoglobulin genes. Nature 408:216-21

51. Muramatsu M, Kinoshita K, Fagarasan S, Yamada S, Shinkai Y, Honjo T. (2000) Class switch recombination and hypermutation require activation-induced cytidine deaminase (AID), a potential RNA editing enzyme. Cell 102:553-63.

52. Martin A, Bardwell PD, Woo CJ, Fan M, Shulman MJ, Scharff MD. (2002) Activation-induced cytidine deaminase turns on somatic hypermutation in hybridomas. Nature 415:802-6.

53. Petersen-Mahrt SK, Harris RS, Neuberger MS. (2002) AID mutates E. coli suggesting a DNA deamination mechanism for antibody diversification. Nature 418:99-103.

54. Honjo T, Kinoshita K, Muramatsu M. (2002) Molecular mechanism of class switch recombination: linkage with somatic hypermutation. Annu. Rev. Immunol. 20: 165-96.

55. Kinoshita K, Honjo T. (2001) Linking class-switch recombination with somatic hypermutation. Nat. Rev. Mol. Cell Biol. 2:493-503.

56. Faili A et al. (2002) AID-dependent somatic hypermutation occurs as a DNA single-strand event in the BL2 cell line. Nat. Immunol. 3:815-21.

57. Lantto J, Ohlin M. (2002) Functional consequences of insertions and deletions in the complementarity-determining regions of human antibodies. J. Biol. Chem. 277:45108-14.

58. Brard F, Shannon M, Prak EL, Litwin S, Weigert M (1999) Somatic mutation and light chain rearrangement generate autoimmunity in anti-single-stranded DNA transgenic MRL/Ipr mice. J. Exp. Med. 190:691-704.

59. Sekiguchi DR, Eisenberg RA, Weigert M. (2003) Secondary heavy chain rearrangement: a mechanism for generating anti-double-stranded DNA B cells. J. Exp. Med. 197:27-39.

60. Van Snick J, Coulie P. (1983) Rheumatoid factors and secondary immune responses in the mouse. I. Frequent occurrence of hybridomas secreting IgM anti-lgGl autoantibodies after immunization with protein antigens. Eur. J. Immunol. 13: 890-4.

61. Coulie P, Van Snick J. (1983) Rheumatoid factors and secondary immune responses in the mouse. II. Incidence, kinetics and induction mechanisms. Eur. J. Immunol. 13:895-9.

62. Coulie PG, Van Snick J. (1985) Rheumatoid factor (RF) production during anamnestic immune responses in the mouse. III. Activation of RF precursor cells is induced by their interaction with immune complexes and carrier-specific helper T cells. J. Exp. Med. 161:88-97.

63. Bogen B, Malissen B, Haas W. (1986) Idiotope-specific T cell clones that recognize syngeneic immunoglobulin fragments in the context of class II molecules. Eur. J. Immunol. 16:1373-8.

64. Munthe LA, Kyte JA, Bogen B. (1999) Resting small B cells present endogenous immunoglobulin variable-region determinants to idiotope-specific CD4(+) T cells in vivo. Eur. J. Immunol. 29:4043-52

65. Klein $U$ et al. (1998) Somatic hypermutation in normal and transformed human B cells. Immunol. Rev. 162:261-80. 